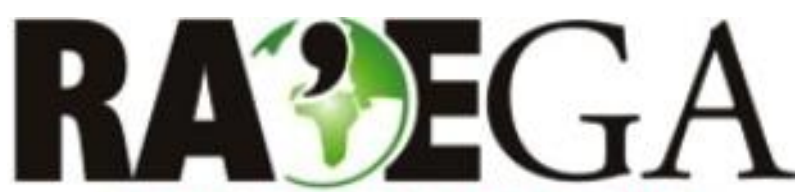

O ESPACYO GEOGRÁFICO EM ANÁLISE

\title{
OBRAS DE CONTENÇÃO DE ENCOSTAS EM BLUMENAU-SC: OLHARES À LUZ DA ENGENHARIA NATURAL
}

\section{SLOPES STABILIZATION WORKS IN BLUMENAU-SC PERSPECTIVES THROUGH NATURAL ENGINEERING}

João Marcos Bosi Mendonça de Mouraํㅜ, André Ricardo Loewen², Juarês José Aumond³

\section{RESUMO}

Na bacia hidrográfica do rio Itajaí, o desastre socioambiental do ano de 2008 revelou-se como um fenômeno de proporção extrema, sobretudo devido ao número de vítimas, das perdas econômicas e dos movimentos de massa. Diante deste cenário, o Governo do Estado de Santa Catarina executou algumas medidas emergenciais e de recuperação, incluindo obras de estabilização de encostas no município de Blumenau-SC. Considerando a relevância destas obras para o desenvolvimento regional e a gestão de risco de desastre do município, o estudo investigou as referidas obras por meio de um checklist e à luz dos princípios da engenharia natural. Refletiu-se, também, sobre a abordagem de engenharia utilizada e se apontaram significativas oportunidades com a aplicação da engenharia natural na contenção de encostas do município.

Palavras-chave: Desenvolvimento sustentável; Bioengenharia de solo; Obras de terra; Desastre socioambiental.

\section{ABSTRACT}

In the basin of Itajaí River, the socio-environmental disaster of 2008 was revealed as a phenomenon of extreme proportions, mainly due to the number of victims, economic losses and mass movements. Faced with this scenario, the Government of Santa Catarina State performed some measures, both emergencies and recovering, including works with slopes stabilization in the city of Blumenau-SC. Considering the relevance of these works for regional development and disaster risk management, the study investigated these works by using a checklist in accordance with the principles of the natural engineering. By reflecting in which engineering approach was used in those solutions, it was found that there are significant opportunities with the application of natural engineering in the slopes stabilization of the city.

Key-words: Sustainable Development; Bioengineering; Earth Works; Socio-Environmental Disaster.

Recebido em: 15/12/2016

Aceito em: 31/07/2018

\footnotetext{
${ }_{1}^{1}$ Universidade Regional de Blumenau, Programa de Pós-Graduação em Engenharia Ambiental, Blumenau/SC, email: joaomarcosmm@hotmail.com

2 Universidade Regional de Blumenau, Programa de Pós-Graduação em Engenharia Ambiental, Blumenau/SC, email: andre_loewen@hotmail.com

${ }^{3}$ Universidade Regional de Blumenau, Programa de Pós-Graduação em Desenvolvimento Regional, Blumenau/SC, email: juares.aumond@gmail.com
} 


\section{OBRAS DE CONTENÇÃO DE ENCOSTAS EM BLUMENAU-SC: OLHARES À LUZ DA ENGENHARIA} NATURAL

\section{INTRODUÇÃO}

Os problemas das áreas de riscos estão sendo perpetuados por fatores econômicos, políticos, sociais e culturais. A crise econômica e social, as políticas habitacionais, historicamente ineficientes, a ineficácia dos sistemas de controles do uso e ocupação dos solos, a inexistência de uma legislação adequada para áreas suscetíveis a riscos e a falta de conhecimento técnico constituem os fatores que têm agravado esse quadro (BRASIL, 2007).

O desastre socioambiental do ano de 2008 na bacia hidrográfica do rio Itajaí revelou parte destes problemas e a vulnerabilidade intrínseca às condições geohidrometeorológicas às quais a população da região encontra-se exposta (KOBIYAMA; MICHEL; GOERL, 2012; FRAGA, 2001). Destacou-se este evento no cenário nacional e internacional, devido às elevadas precipitações, que em dois dias apresentavam quantitativos que superaram todas as previsões esperadas para aqueles dois meses (CORDERO et al., 2009). Essas precipitações, anormalmente concentradas num curto período de tempo em uma área geográfica e historicamente vulnerável aos desastres socioambientais, desencadeou a maior tragédia geoclimática catarinense já registrada (AUMOND; BACCA, 2012).

Ademais, diferentemente dos outros casos já registrados na região, observou-se a ocorrência simultânea de três tipos de eventos desencadeadores do desastre, são eles: a inundação gradual, inundação brusca (enxurrada) e os movimentos gravitacionais de massa.

Com relação aos movimentos de massa, houve um número significativo destes, sobretudo do tipo escorregamentos (slides), rastejo (creep) e corridas de massa (flows) onde as encostas apresentavam-se morfologicamente como coletoras ou, em outras palavras, como superfícies concentradoras de água e energia. Não suficientemente, a geomorfologia acidentada e os solos profundos (e ainda expostos pelo processo de urbanização), também exerceram influência na distribuição espacial dos escorregamentos (AUMOND; SEVEGNANI, 2009).

Diante deste cenário pós-2008, o Governo do Estado de Santa Catarina executou algumas medidas emergenciais e de resposta (BRASIL, 2012) frente aos inúmeros deslizamentos de terra na região. No que se refere à estabilização de encostas, foram executadas obras de contenção no município de Blumenau-SC.

Considerando a relevância das estruturas para o desenvolvimento regional, a segurança e a vida da população do município, e também sua aplicabilidade em conjunto com diversas obras de infraestrutura (NEVES; HENKES, 2013), o presente artigo visou a refletir, à luz da engenharia natural, sobre as obras de contenção de encostas realizadas pelo Governo do Estado de Santa Catarina. O estudo delimitou-se em dez estruturas construídas no pós-desastre de 2008.

Visto que é frequente a realização de obras de contenção de encostas no município, e que tem crescido o interesse pela engenharia natural no Brasil, a pesquisa pretendeu abrir uma discussão sobre a abordagem da engenharia tradicional (atual) aplicada a estas obras de significativa relevância social. Não se pretende, com isso, esgotar a temática e lançar-se em defesa desta ou de outra abordagem. O que se objetiva é dialeticamente contextualizar e problematizar a engenharia tradicional, oportunizando um panorama do que já existe (diagnósticos das obras) e de como a engenharia natural poderia contribuir positivamente. Este artigo, portanto, pretende contribuir para subsidiar as ações de planejamento e gestão pública na escolha das obras de recuperação e restauração de encostas com ênfase nas obras de engenharia natural, apontando aspectos da paisagem que se constituem relevantes para a melhoria da gestão ambiental urbana (LI; MANDER, 2009; GENGO; HENKES, 2013). 


\section{OBRAS DE CONTENÇÃO DE ENCOSTAS EM BLUMENAU-SC: OLHARES À LUZ DA ENGENHARIA NATURAL}

\section{MOVIMENTOS DE MASSA: CLASSIFICAÇÕES E DINÂMICAS \\ A conformação fortemente acidentada} do relevo de Blumenau faz com que $58 \%$ de sua área total sejam encostas (VIEIRA; FURTADO, 2005). Diante deste contexto, ao abordar medidas de recuperação de ambientes naturais e construídos, observamos a necessidade de compreender, sobretudo, os fatores constituintes da suscetibilidade aos movimentos de massa. Isto não significa desconsiderar os fatores políticos e culturais constituintes do desastre (JACOBI, GÜNTHER, GIATTI, 2012; NASCIMENTO; GOMES, 2014). Trata-se apenas de compreender melhor alguns dos processos desencadeadores dos desastres socioambientais. Assim sendo, como se desenvolveram e desenvolvem os movimentos de massa no município de Blumenau-SC?

De acordo com Aumond e Sevegnani (2009) podem-se elencar três principais tipos de movimentos de massa: o rastejo, a corrida de massa e os escorregamentos. No primeiro caso, o movimento tipo rastejo (Figura 1) se caracteriza pelos seus movimentos lentos, sem geometria definida e que podem incluir solo, rocha alterada e fraturada (SANTOS, 2007). Trata-se de deslocamentos sutis e notadamente frequentes na área urbana da região sul do município em estudo, BlumenauSC, e que podem ser identificados pela presença de árvores e postes inclinados.

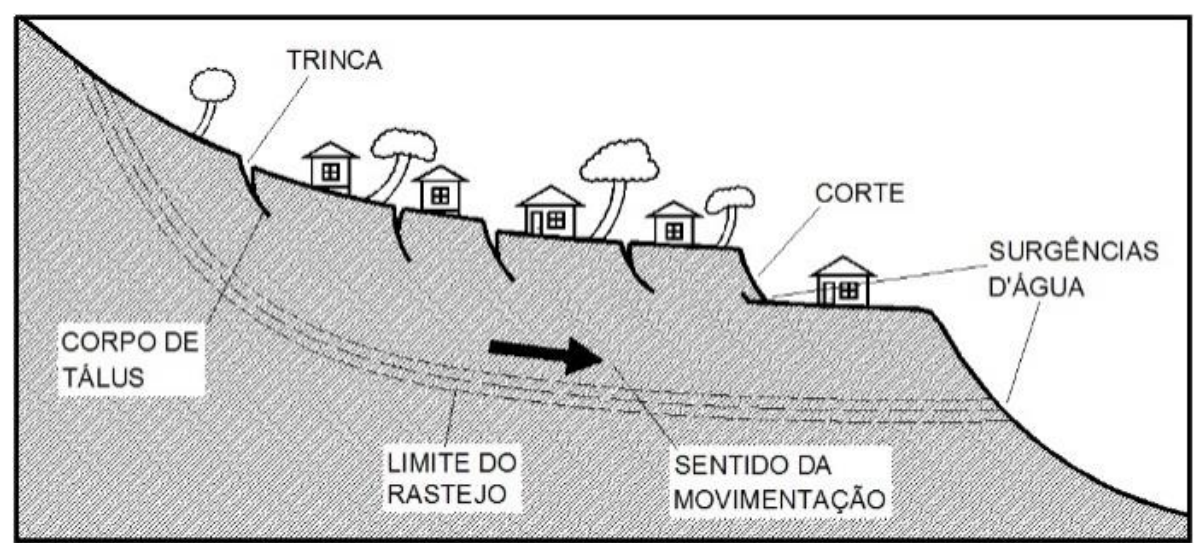

Figura 1 - Movimento de massa do tipo rastejo. Fonte: Adaptado de IPT-SP (1991).

Já referente às corridas de massa (Figura 2), observa-se um escoamento de massa significativamente veloz e geralmente de grandes dimensões, apresentando-se com uma dinâmica mais fluída (HIGLAND; BOBROWSKY,
2011). Este foi um dos movimentos de massa que causaram maiores prejuízos e as maiores perdas de vidas humanas no desastre de 2008 (AUMOND; SEVEGNANI, 2009). 


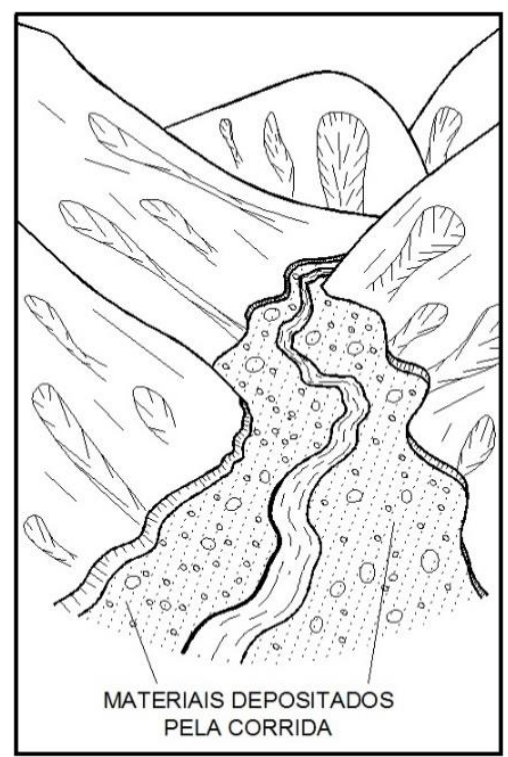

Figura 2 - Escorregamentos do tipo corrida de massa. Fonte: Adaptado de IPT-SP (1991).

\section{Concernente aos escorregamentos}

(Figura 3) pode-se afirmar que foram os mais comuns ocorridos em 2008, devido à topografia e à presença de solos profundos, típicos da região da Serra do Mar. Observa-se neste tipo de movimentos três formas geométricas predominantes: (1) planar; (2) circular; e em (3) cunha. Há também o movimento caracterizado como queda de blocos, onde blocos de rochas das formas mais variadas se desprendem e caem com elevada velocidade. Estes, porém, foram menos frequentes no desastre de 2008.

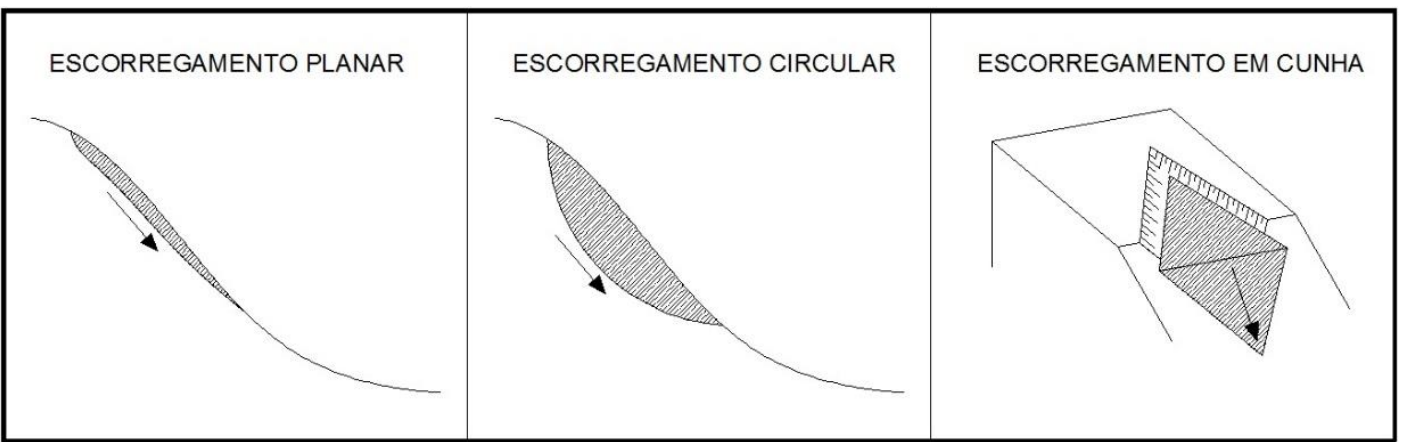

Figura 3 - Escorregamentos do tipo planar, circular e em cunha. Fonte: Adaptado de IPT-SP (1991).

\section{ENGENHARIA NATURAL: OPORTUNIDADES E TÉCNICAS}

Tendo em vista estes aspectos citados, a engenharia, tradicionalmente, tem abordado medidas de contenção de encostas partindo da premissa de priorizar obras estruturais (gabiões, muros de pedra, arrimo, estruturas ancoradas) em detrimento de obras não estruturais (retaludamento, aterro, proteção superficial natural). Deste modo, as obras têm priorizado e se concentrado mais nos efeitos do que nas causas dos movimentos gravitacionais de massa.

Em alguns casos, estas obras para o poder público, além de custosas, ignoram o contexto ecológico local e o potencial de serviço dos sistemas vivos (OLIVEIRA; RECKZIEGEL; ROBAINA, 2006). Ao passo que em obras que se utilizam das técnicas de engenharia natural, notam-se benefícios relativos ao tempo de execução, custo global (envolvendo todas as fases da obra) e sustentabilidade ambiental (Figura 4). Esta 


\section{OBRAS DE CONTENÇÃO DE ENCOSTAS EM BLUMENAU-SC: OLHARES À LUZ DA ENGENHARIA} NATURAL

abordagem promove a regularização dos custos de obras ao longo do processo de gestão e monitoramento. Em contrapartida, os custos de construção e reabilitação tendem a ser significativamente menores, diminuindo os picos de investimento na construção e na reabilitação (Figura 4).

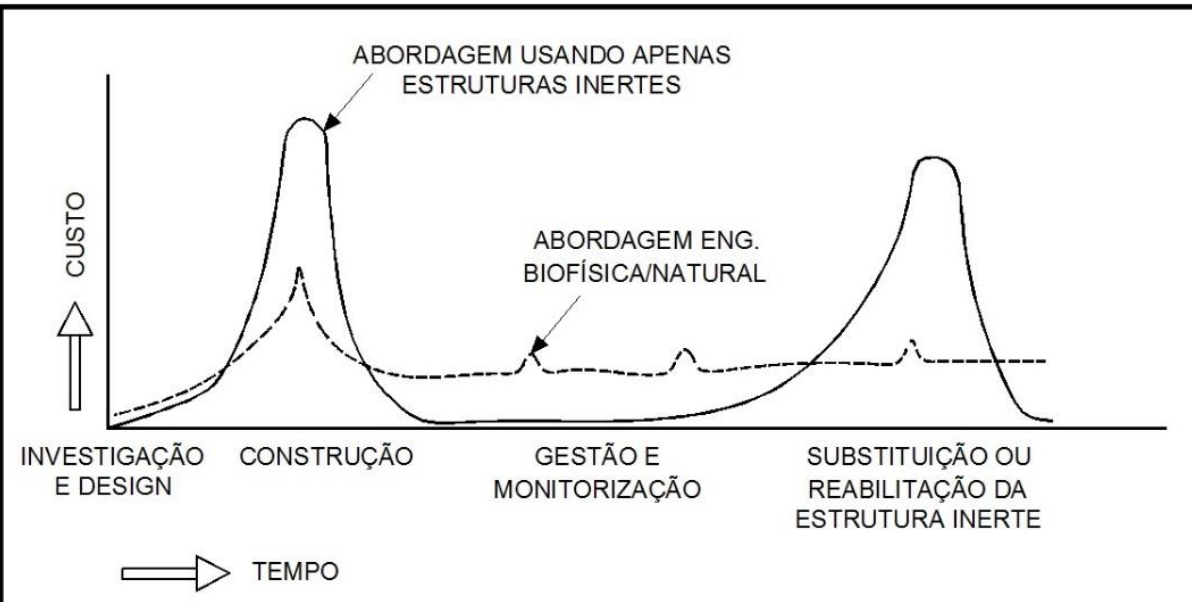

Figura 4 - Comparativo entre custos médios de obras com diferentes abordagens (tradicional versus natural). Fonte: Adaptado de IPT-SP (1991).

Segundo Silva (2012), a engenharia natural, ou bioengenharia de solo, é uma abordagem que objetiva a estabilização de taludes e encostas, através do emprego de materiais vivos ou combinados com materiais inertes. Neste sentido, ela "[...] diferencia-se de certo modo das outras formas mais clássicas de engenharia ao colocar, como princípio condutor fundamental dessa sua intervenção, a imposição de respeito pela dinâmica funcional e sistêmica da Natureza" (EPAL, 2011, p.9).

A bioengenharia ainda é pouco conhecida e utilizada no Brasil devido ao conhecimento insuficiente sobre as propriedades, características e funções das espécies vegetais utilizáveis em obras de contenção de encostas e revitalização de cursos d'água. No entanto, nos Estados Unidos e Europa, as técnicas de bioengenharia têm sido cada vez mais reconhecidas e utilizadas como excelentes alternativas na recuperação ambiental e no combate aos processos erosivos. De acordo com Morgan e Rickson (1975), a engenharia natural já é reconhecida como uma alternativa em obras da engenharia civil.
É válido destacar que a engenharia natural pode, por vezes, ser um substituto para a engenharia clássica/tradicional, contudo, não raras vezes é utilizada como uma abordagem útil para aperfeiçoar a última. Isto ocorre mesmo que as intervenções baseadas na engenharia natural se diferenciem daquelas praticadas pela engenharia tradicional, devido em grande parte à significativa importância dada às condições ecológicas do local, especialmente, aos parâmetros ligados com o desenvolvimento da vegetação (SILVA, 2012). Assim, a engenharia natural se caracteriza:

[...] mais pela orientação das funções e processos naturais, do que pela sua substituição por sistemas exteriores artificiais. A vantagem desta forma de intervenção era a de que, ao trabalhar com os Sistemas Naturais e não contra eles, se obtinham resultados idênticos com muito menores custos de manutenção e com crescente eficácia (EPAL, 2011, p. 5).

Sem dúvidas, para tamanho desafio exige-se uma prática interdisciplinar, típica dos estudos voltados às ciências ambientais (PHILLIPI JUNIOR et al., 2000). A interdisciplinaridade permeia os projetos de engenharia natural, de modo que 


\section{OBRAS DE CONTENÇÃO DE ENCOSTAS EM BLUMENAU-SC: OLHARES À LUZ DA ENGENHARIA NATURAL}

metodologicamente seja capaz de potencializar a integração de disciplinas antes desassociadas. Assim, propõe-se um conjunto de conhecimentos orientados à cooperação com os sistemas naturais. São alguns exemplos de áreas que se integram na práxis da engenharia natural: a ecologia da paisagem, a avaliação ecológica, a educação ambiental, materiais e técnicas de construção, sistema de informações geográficas (SIG), economia, direito ambiental, planejamento e gestão ambiental, pedologia, climatologia, hidrologia e hidráulica, geologia de engenharia e sistemas construtivos com materiais vivos (QUINTA-NOVA, 2013).

Em resumo, a engenharia natural aborda, por meio destes princípios e disciplinas, a construção de um território sustentável associado à conservação da natureza e da biodiversidade. Não obstante, devem ser avaliadas as vantagens e limitações da biotecnologia, considerando-se uma série de aspectos condicionantes, tais como: geologia, clima, pedologia, hidrografia, hidrologia, vegetação local e os agentes sociais envolvidos (SOLERA, 2009). Por isso a utilização da engenharia natural passa necessariamente por uma mudança de postura dos projetistas de recuperação e restauração ambiental, devendo assumir uma visão sistêmica e geográfica na qual estarão inseridas as obras projetadas.
As biotécnicas utilizam de forma integrada e complementar os elementos mecânicos (estruturas), combinados com elementos biológicos (vegetais) para deter e prevenir os processos de deslizamentos e de erosão (GRAY; LEISER, 1982).

Os gabiões-vivos são exemplos de estruturas que se utilizam da abordagem de engenharia natural (EPAL, 2011). Sua forma é retangular, executada com malha de arame galvanizado e preenchida com material inerte. Estacas vivas são inseridas no interior dos gabiões em filas na primeira malha do gabião superior ou com disposição irregular, prevenindo a erosão e ancorando a margem em caso de instabilidades de ordem física e/ou mecânica. Na introdução da vegetação, durante o processo de enchimento, colocam-se camadas de terra e dispõem-se plantas enraizadas com um comprimento capaz de atingir plenamente o solo na face interna do gabião. Busca-se assim a maximização da estabilidade da estrutura. O objetivo é o de que o desenvolvimento das raízes auxilie na fixação da estrutura ao talude e melhore a sua integração ecológica. Na Figura 5 se observam os componentes listados do sistema e um exemplo de aplicação da estrutura em Osasco, São Paulo.

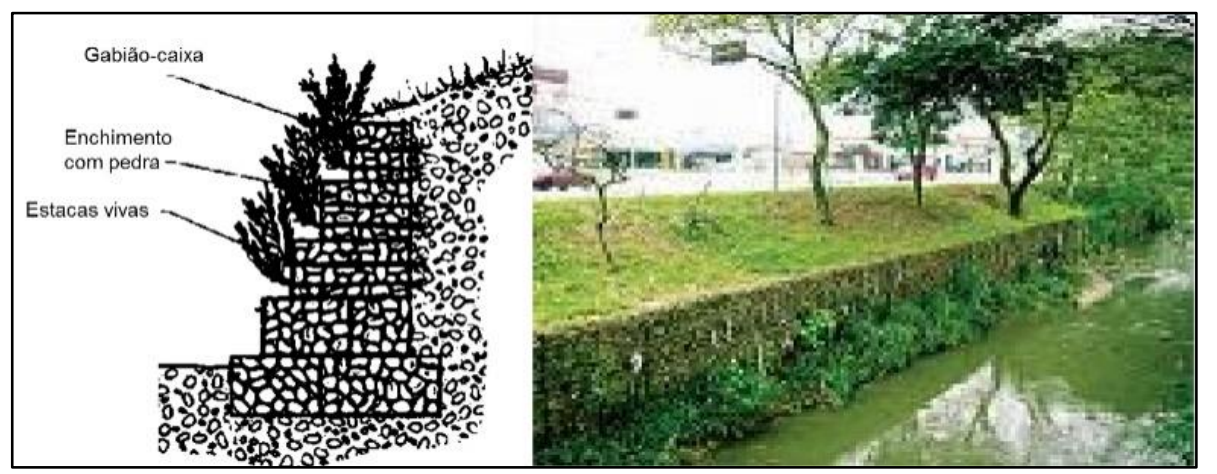

Figura 5 - Gabião-vivo em perfil e aplicados em uma encosta. Fonte: EPAL (2011) e Solera (2009).

No Brasil, existem experiências com a bioengenharia bem-sucedidas com a aplicação da engenharia natural na recuperação de áreas degradadas. É o exemplo do caso do Arroio Guarda Mor, no município de Faxinal do
Soturno (Rio Grande do Sul). Na localidade, ocorreram problemas de instabilidade da encosta do rio intensificados por ações antropogênicas (DURLO; SUTILI, 2005). 


\section{OBRAS DE CONTENÇÃO DE ENCOSTAS EM BLUMENAU-SC: OLHARES À LUZ DA ENGENHARIA NATURAL}

Assim, no trecho com $40 \mathrm{~m}$ de extensão, optou-se pela construção de uma parede vegetada de madeira, utilizando material vegetativo como as mudas e estacas vivas, e como material construtivo troncos de eucalipto, estacas roliças, arames e grampos de cerca. Realizou-se a inserção de estacas vivas de forma ordenada sobre o talude para dar início ao reflorestamento e estabilizar a encosta. Na Figura 6, é possível observar os cenários pré e pós-intervenção com este tipo de medida.

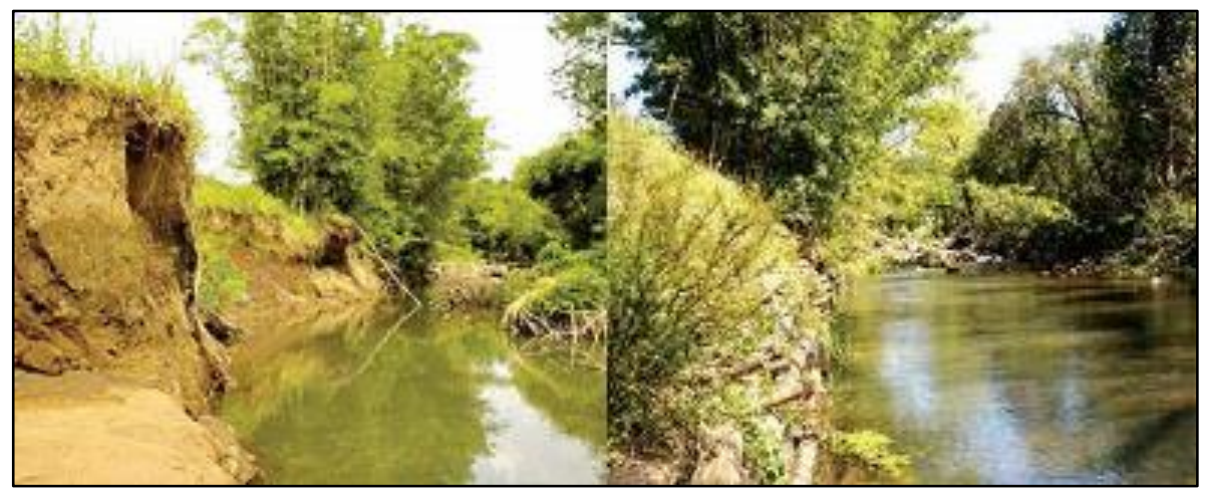

Figura 6 - Antes e depois da aplicação de técnicas da engenharia natural em encosta de rio. Fonte: Durlo e Sutili (2005).

Holanda et al. (2009) analisaram as formas de controle da erosão das margens dos cursos d'água do estado de Sergipe. Observouse que a população ribeirinha tem procurado mitigar o processo erosivo das margens dos cursos d'água por meio do uso de materiais locais (sacos de areia, borracha de câmara de ar) e de baixo custo. Por parte do poder público, iniciativas de aplicação da bioengenharia de solos também foram identificadas, protegendo o talude dos rios com um rápido desenvolvimento da vegetação.

São estes exemplos de obras de engenharia natural que se norteiam pelo princípio da mínima intervenção possível na dinâmica ambiental. Com isso, espera-se otimizar benefícios ambientais e sociais, em detrimento dos impactos negativos gerados frequentemente por intervenções descontextualizadas do seu ambiente.

\section{MATERIAIS E MÉTODOS}

Abordados os processos envolvidos na dinâmica dos movimentos de massa, das obras de contenção de encostas e da engenharia natural como alternativa construtiva, define-se agora a metodologia da presente pesquisa científica. Trata-se de um estudo de caso, ocorrido no município de Blumenau-SC, e que buscou discutir sobre as obras de contenção de encostas realizadas após o desastre socioambiental de 2008.

\section{1. ÁREA DE ESTUDO}

O município de Blumenau encontra-se numa zona de transição entre o curso médio e inferior do Rio Itajaí, em área de abrangência da Faixa de Dobramentos Remobilizados na Unidade Geomorfológica da Serra do Mar (ATLAS DE SANTA CATARINA, 1986). Com população de 348.513 habitantes (IBGE, 2018), o município se enquadra como mais populoso do Vale do Itajaí e terceiro mais populoso do Estado.

Do ponto de vista geológico, segundo Xavier (1996), encontram-se em Blumenau quatro unidades estratigráficas distintas, sendo elas: Complexo Luiz Alves, Complexo Metamórfico Brusque, Grupo Itajaí e Sedimentos Aluvionares (Figura 7).

Nota-se a presença das obras investigadas (em vermelho na Figura 7) no Complexo Luiz Alves, nos Sedimentos Aluvionares e no Grupo Itajaí. Neste último, observa-se um conjunto de sedimentos predominantemente detríticos, encimados e 


\section{OBRAS DE CONTENÇÃO DE ENCOSTAS EM BLUMENAU-SC: OLHARES À LUZ DA ENGENHARIA} NATURAL

atravessados por granitos e riolitos. Segundo estudos desenvolvidos pelo Instituto de Pesquisa e Planejamento Urbano de Blumenau (IPPUB, 1996) e Xavier, F. (1996), esta área apresenta os maiores problemas para urbanização, em função da sua alta suscetibilidade a escorregamentos.

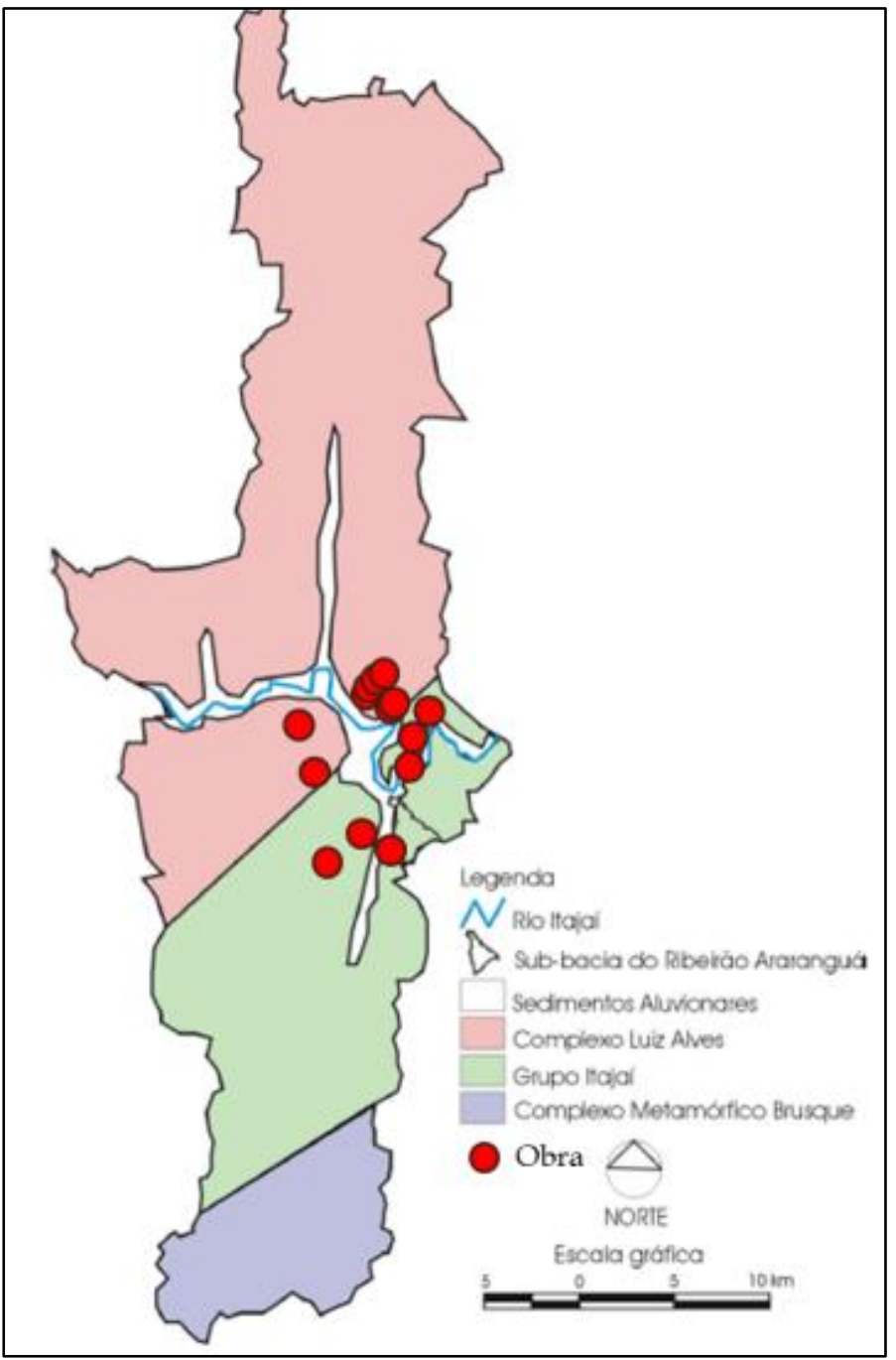

Figura 7 - Geologia do município de Blumenau e local das obras pesquisadas. Fonte: Adaptado de Xavier (1996).

\subsection{OBRAS DE CONTENÇÃO DE ENCOSTAS}

Através do banco de dados da Agência de Desenvolvimento Regional do Estado de Santa Catarina, foi possível identificar 10 obras de contenção de encostas (Quadro 1). Estas fazem parte das primeiras obras realizadas após o desastre de 2008, ou seja, trata-se de obras de caráter emergencial e enquadradas como medidas de reabilitação/reconstrução (BRASIL, 2012). 
OBRAS DE CONTENÇÃO DE ENCOSTAS EM BLUMENAU-SC: OLHARES À LUZ DA ENGENHARIA NATURAL

\begin{tabular}{|c|c|c|c|}
\hline № & Município & Endereço / Tipo de Ocorrência & Obra \\
\hline 1 & Blumenau & $\begin{array}{c}\text { Rua Stuttgart - Bairro Ponta Aguda } \\
\text { / (Escorregamento de talude) }\end{array}$ & Aterro e Gabião \\
\hline 2 & Blumenau & $\begin{array}{c}\text { Rua Oscar Burger / } \\
\text { Valparaíso(Escorregamento de } \\
\text { aterro) }\end{array}$ & $\begin{array}{l}\text { Retaludamento, Gabião e } \\
\text { Enrocamento }\end{array}$ \\
\hline 3 & Blumenau & $\begin{array}{l}\text { Rua Henrique Reif - Entr. Ruas } \\
\text { Jorge João Deschamps e } \\
\text { Copacabana / Ponta Aguda } \\
\text { (Escorregamento de aterro) }\end{array}$ & Retaludamento e Gabião \\
\hline 4 & Blumenau & $\begin{array}{c}\text { Rua Amazonas / (Escorregamento } \\
\text { de aterro) }\end{array}$ & Retaludamento \\
\hline 5 & Blumenau & $\begin{array}{l}\text { Rua Silvano Candido da Silva } \\
\text { Junior / Ponta Aguda(Erosão / } \\
\text { Deslizamento de talude de aterro) }\end{array}$ & Enrocamento \\
\hline 6 & Blumenau & $\begin{array}{c}\left.\text { Rua Bahia (em frente ao } n^{\circ} 8523\right) / \\
\text { (Escorregamento de talude) }\end{array}$ & Enrocamento \\
\hline 7 & Blumenau & $\begin{array}{c}\text { Rua Petrolândia (em frenteao } \mathrm{n} \text { 여) } \\
\text { / Água Verde (Escorregamento de } \\
\text { talude) }\end{array}$ & Retaludamento \\
\hline 8 & Blumenau & $\begin{array}{c}\text { Rua Copacabana - Bairro Fortaleza } \\
\text { / (Erosão de talude de aterro) }\end{array}$ & Retaludamento \\
\hline 9 & Blumenau & $\begin{array}{c}\text { Rua Emílio Talmann - Bairro Garcia } \\
\text { (Erosão da margens do Ribeirão } \\
\text { Garcia) }\end{array}$ & Gabião / Drenagem \\
\hline 10 & Blumenau & $\begin{array}{l}\text { Rua República Argentina } \\
\text { (Deslizamento de talude) }\end{array}$ & Gabião / Drenagem \\
\hline
\end{tabular}

Quadro 1 - Localização das obras de contenção de encostas. Fonte: Autores (2015).

\subsection{TÉCNICA EMPREGADA}

Para a coleta de dados, as observações de campo foram descritas a partir de um checklist desenvolvido pelos autores (Apêndice A). O checklist não pretendeu esgotar a análise das obras, mas apenas registrar aspectos técnicos e ambientais relevantes, que possibilitem uma reflexão sobre a abordagem de engenharia utilizada e as suas implicações para o ambiente. A discussão dos resultados obtidos, por sua vez, se deu por meio do agrupamento de classificação das respectivas obras, sendo possível que uma mesma obra pertença a vários grupos, ou seja, tenha diversos tipos de estruturas: obras com retaludamento, enrocamento e gabião-caixa.

\section{RESULTADOS E DISCUSSÃO}

Das 10 obras investigadas, observaram-se 4 com patologia visível e identificável e 6 sem patologia visível e identificável. Dentre as 4 com problemas técnicos, nota-se a presença de processos erosivos já consolidados devido à exposição do solo, deslocamento excessivo da estrutura (embarrigamento), inclinações excessivas, taludes com patamares inadequados (inclinação, superfície), ausência de calhas e outras estruturas de drenagem. Ou seja, nesta abordagem, $40 \%$ dos locais apresentam significativo risco de desestabilização de sua encosta por não considerar aspectos técnicos e ambientais.

Já a respeito da geomorfologia das encostas, notou-se o predomínio das encostas tipo coletoras de água com perfil côncavo, como se observa no modelo e na imagem da Figura 8. 

NATURAL

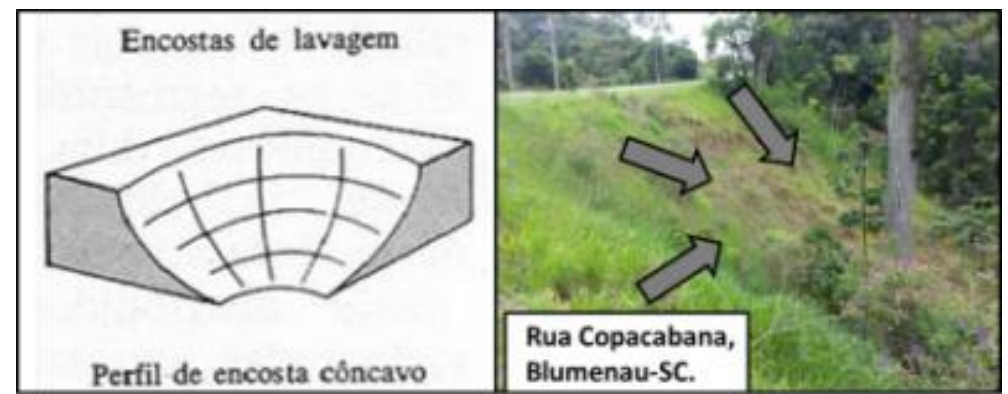

Figura 8 - Geomorfologia predominante das encostas estudadas. Fonte: Adaptado de Aumond e Sevegnani (2009).

São nestas encostas também, que a maioria das obras com patologia estão localizadas. Como agravante, nelas foi verificada a presença de argissolos espessos. A ausência de vegetação herbácea nestas áreas, como arbustos rasteiros e plantas de raízes densas superficiais, é um fator que contribui para o aumento da suscetibilidade de novos movimentos de massa no local, além da intensificação dos processos erosivos. Tal observação reforça ainda mais a necessidade de uma abordagem de engenharia que seja capaz de articular estes conhecimentos das ciências naturais, com os fatores físicomecânicos das obras de contenção de encostas.

Realizada esta visão geral das obras pesquisadas, a seguir são discutidas as obras de contenção de encostas de acordo com características construtivas (retaludamento, enrocamento e gabião-caixa).

\subsection{OBRAS DE RETALUDAMENTO}

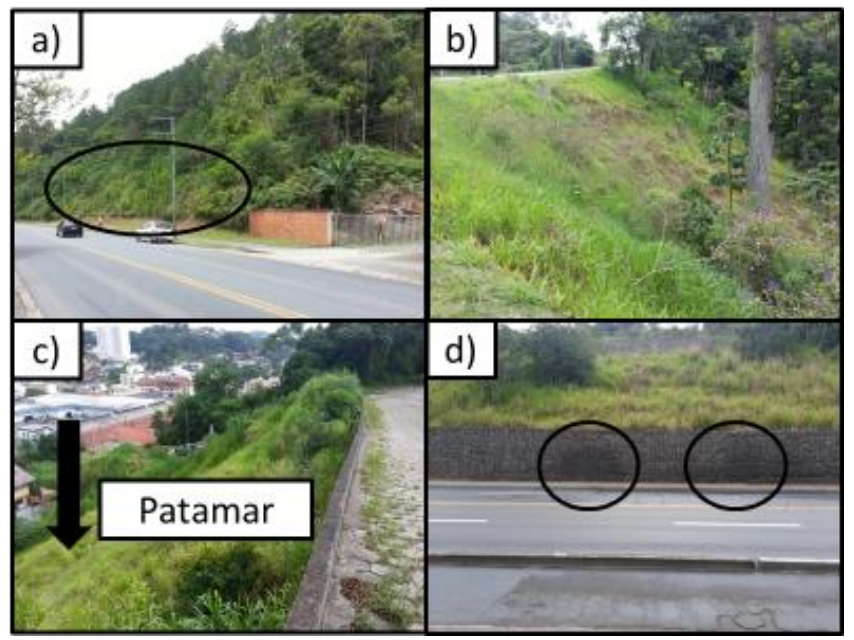

Figura 9 - Obras pesquisadas com retaludamento de encostas. Fonte: Autores (2015). 


\section{OBRAS DE CONTENÇÃO DE ENCOSTAS EM BLUMENAU-SC: OLHARES À LUZ DA ENGENHARIA NATURAL}

Na obra da Rua Copacabana (Figura 9b), também foi exclusivamente utilizada a técnica de retaludamento, com as seguintes características identificadas: alta inclinação, insuficiência de patamares e processo de erosão acentuado. Na Figura 10, é possível observar de maneira ampliada estas características (Figura 10).

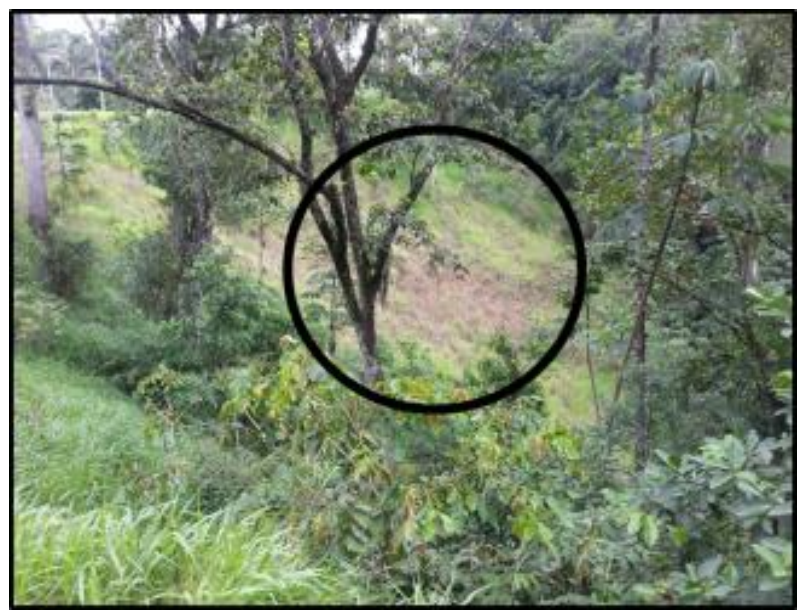

Figura 10 - Erosão sobre a superfície da encosta na obra da Rua Copacabana. Fonte: Autores (2015).

De modo semelhante, apresenta-se na Rua Petrolândia (Figura 9c) uma significativa erosão logo abaixo da via de movimentação de veículos. Não se trata de uma área de grande fluxo de carros (rua sem saída), contudo, notou-se a presença de uma significativa quantidade de moradias a 20 metros da encosta.

Em relação ao talude da Rua Rep. Argentina (Figura 9d), no que diz respeito à geometria dos taludes, nenhuma patologia foi identificada. Salienta-se, todavia, a necessidade de se verificar o sistema de drenagem, visto que, como se pode observar na Figura 9d, o muro de gabião-caixa apresenta manchas de umidade. É possível que as manchas sejam causadas por obstrução dos canais de drenagem, e a obstrução, gerada pelo acúmulo de sedimentos.

Nesse sentido, duas necessidades podem ser destacadas: a manutenção constante e preventiva da estrutura e a minimização dos processos erosivos locais. Tais aspectos, se desconsiderados, colocam a estrutura em um nível de alto risco de colapso, tendo em vista o potencial nocivo que as pressões hidrodinâmicas podem oferecer à estrutura em cenários de eventos extremos (chuvas intensas).

Referente às ruas Stuttgar (Figura 11a) e Oscar Burguer (Figura 11b), nota-se na primeira uma adequada geometria do talude. Entretanto, observa-se a necessidade de implantação de estruturas de drenagem (calhas coletoras) para que a estrutura não seja significativamente prejudicada pela ação da água.

$\mathrm{Na}$ obra da Rua Oscar Burguer (Figura 11b), observou-se a necessidade da realização de patamares, e consequentemente a remoção das moradias na base do morro (indicado pela flecha preta). Neste último caso, percebe-se a necessidade de integração das soluções técnicas de engenharia com as gerenciais, especialmente as de planejamento urbano e territorial. 

NATURAL

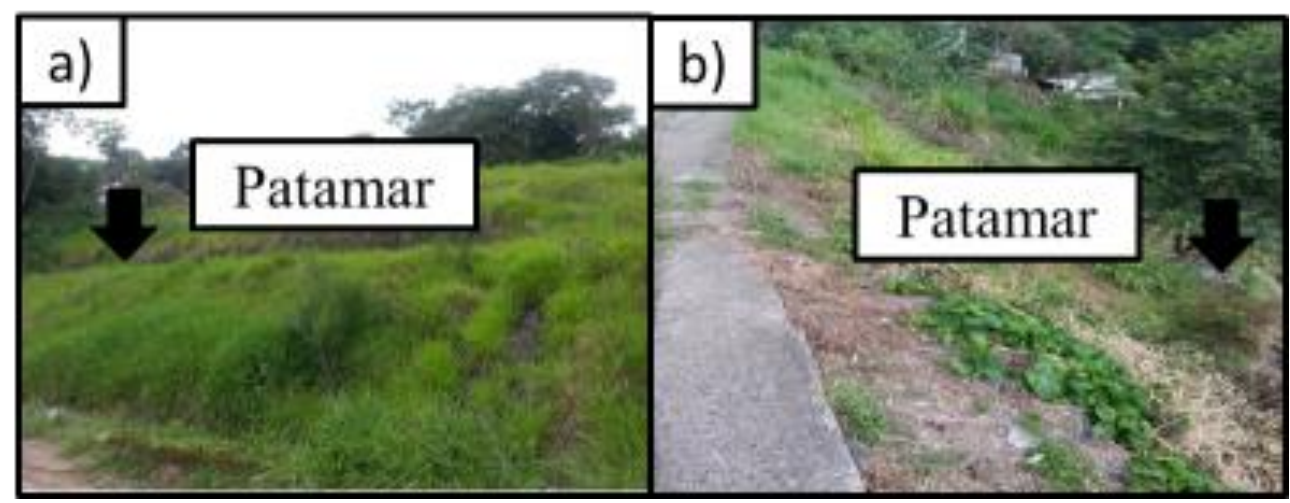

Figura 11 - Erosão sobre a superfície da encosta na obra da Rua Copacabana. Fonte: Autores (2015).

\subsection{OBRAS DE ENROCAMENTO}

Foram três as obras exclusivamente de enrocamento de terra: Rua Bahia (Figura 12a), Rua Silvano Candido (Figura 12b) e Rua Oscar Burguer (Figura 12c). Nenhuma delas apresentou patologia visível. Todavia, salienta- se a necessidade de se avaliar, em todas, aspectos quali-quantitativos da cobertura vegetal, a fim de aumentar a coesão do solo e diminuir a velocidade de escoamentos superficiais.

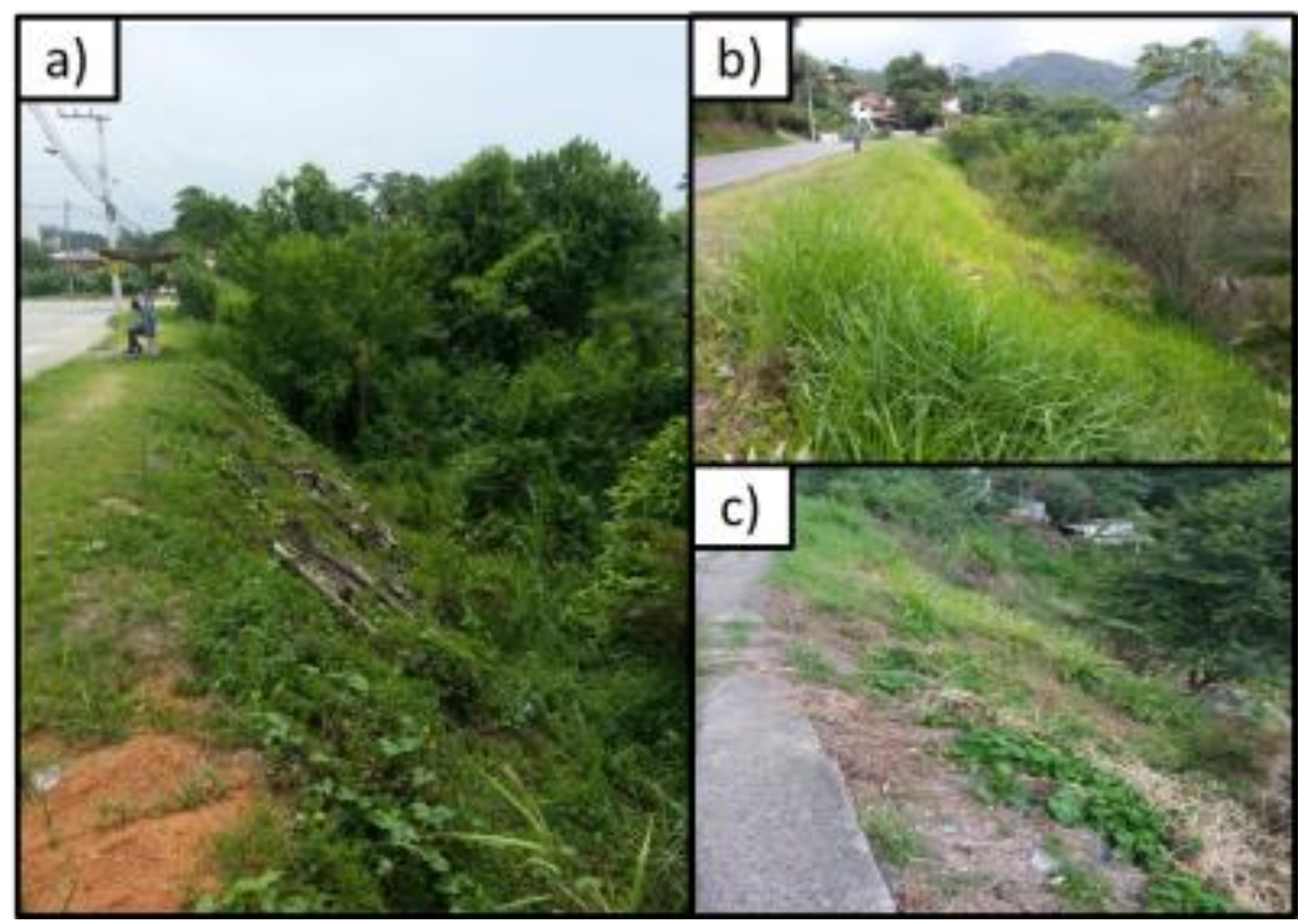

Figura 12 - Obras pesquisadas com enrocamento. Fonte: Autores (2015).

Nesse sentido, a técnica de enrocamento vivo poderia fortalecer a estrutura, diminuindo inclusive com mais eficácia os processos de erosão superficial. Neste caso, poderia ser útil a técnica explanada por Silva (2012) e EPAL (2011), na qual sugerem a escavação de valas perpendiculares à linha de maior inclinação do talude. No seu interior, poderiam ser postas espécies condicionadas à realidade edafoclimática da região e capazes de criar densas filas de arbustos e ramos que mitigam o transporte de sedimentos (COPPIN; RICHARDS, 1990). 


\section{OBRAS DE CONTENÇÃO DE ENCOSTAS EM BLUMENAU-SC: OLHARES À LUZ DA ENGENHARIA NATURAL}

\subsection{OBRAS DE GABIÃO-CAIXA}

São cinco as obras de contenção de encostas nas quais foram aplicadas as técnicas conhecidas como gabião-caixa. Estas obras estão representadas na Figura 13, na seguinte ordem: (a) Rua Henrique Reiff, onde o muro construído em patamares sustenta a via principal; (b) Rua Emílio Talmann, em que se percebe a construção de uma proteção superficial argamassada a fim de elevar o escoamento das águas do ribeirão Garcia; (c)
Rua Stuttgar, em que o gabião encontra-se apoiado sobre um dos patamares do talude; (d) Rua Rep. Argentina, em que se verificou um muro de aproximadamente $100 \mathrm{~m}$ de comprimento e diversas patologias; e (e) Rua Oscar Burguer, em que se observou a incremento de carga (resíduos de madeira) sobre o muro por parte de moradores da região. Entretanto, esta não apresentou patologia visível.

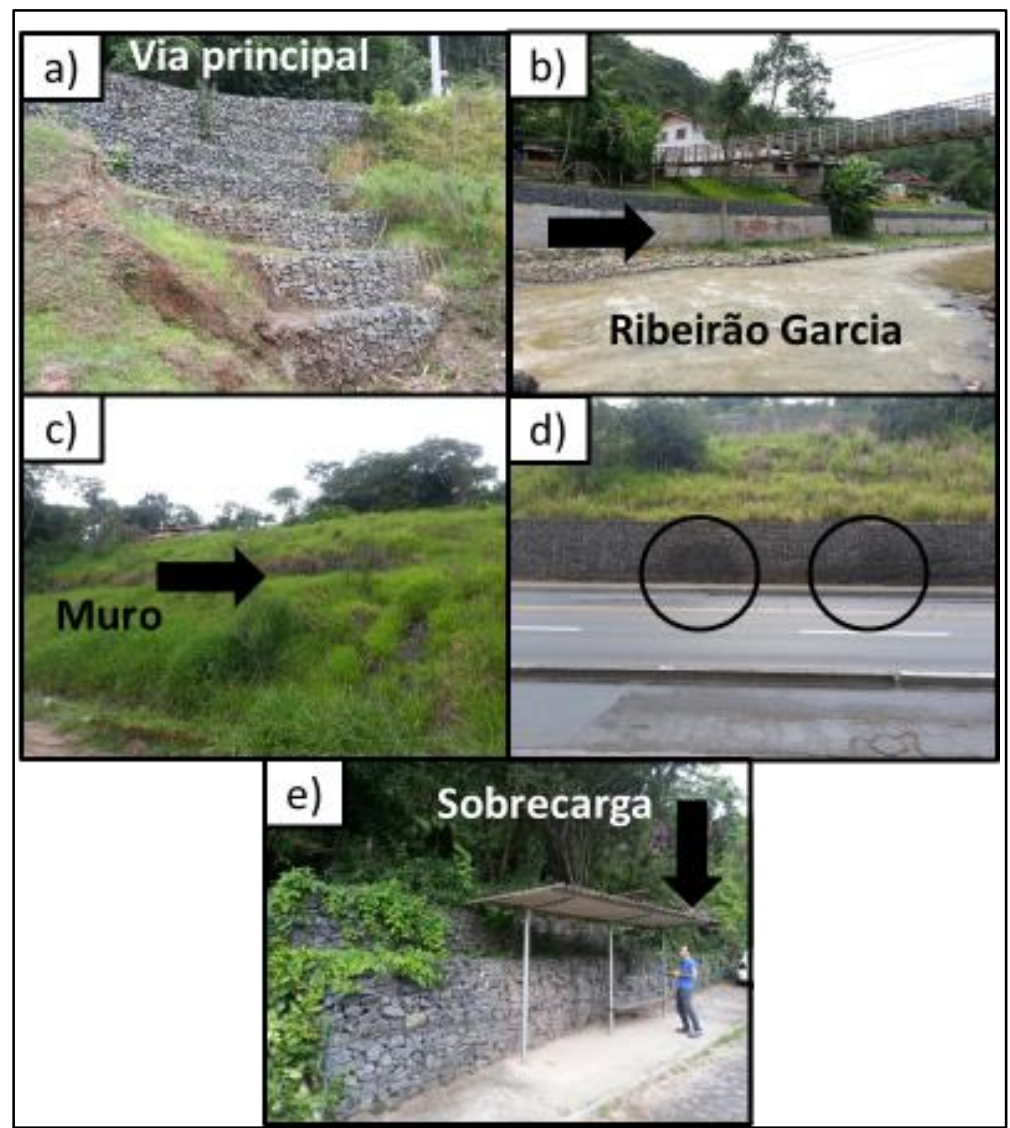

Figura 13 - Obras pesquisadas com gabião-caixa. Fonte: Autores (2015).

A respeito de todas as obras, cabe destacar a insuficiência ou inadequação dos sistemas de drenagens. Nenhuma apresentou estruturas para a coleta da água pluvial. Destaca-se ainda a Rua Emilio Talmann (Figura 13b), onde se pode observar que a água da rede de drenagem tem atingindo a superfície do muro, podendo provocar a erosão da estrutura argamassada (Figura 14). Neste caso, os dutos da rede deveriam ser ampliados em seu comprimento, de modo que a água pluvial não provoque a erosão da camada cimentícia e da margem.

Além disso, uma abordagem que considerasse o emprego de "materiais vivos" em seu entorno poderia servir como uma estrutura de dissipação de energia, reduzindo a velocidade da água, minorando seu potencial erosivo (energia cinética do fluído). Não menos importante, o emprego de "materiais vivos" aumentaria o atrito entre a água e as margens, reduzindo consequentemente a sua vazão à 


\section{OBRAS DE CONTENÇÃO DE ENCOSTAS EM BLUMENAU-SC: OLHARES À LUZ DA ENGENHARIA NATURAL}

jusante, como explica a equação de Manning. Tal fenômeno preveniria impactos negativos à jusante motivados pelo aumento do escoamento da água (erosão e inundação), preservando ao máximo as condições hidrológicas naturais.

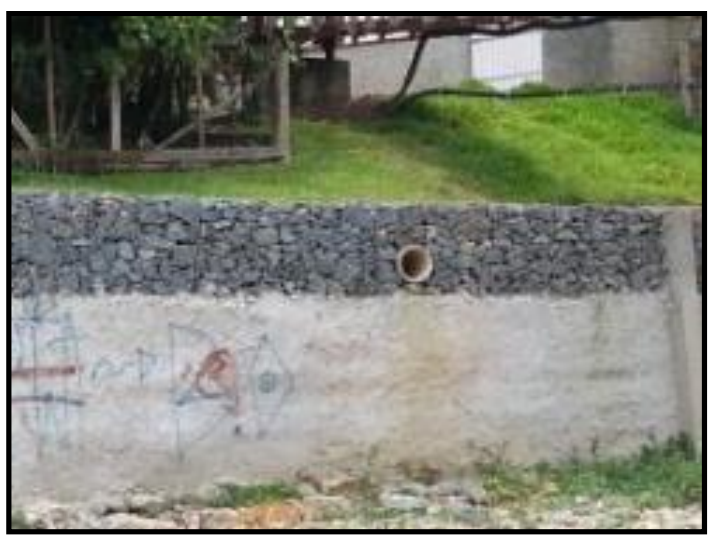

Figura 14 - Tubulação de descarga da água pluvial. Fonte: Autores (2015).

Já referente à Rua Rep. Argentina, destaca-se este como um dos casos mais preocupantes. Além dos indicativos de patologia referente à rede de drenagem (indicados na Figura 13d), o muro se apresentou com um significativo deslocamento, sendo, por isso, imprescindível uma obra de reparação (Figura 15).

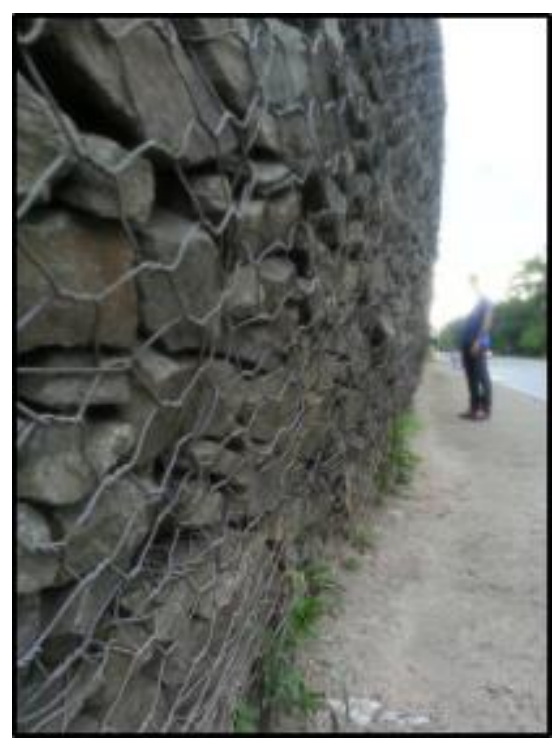

Figura 15 - Deslocamento do muro de gabião-caixa da Rua Rep. Argentina. Fonte: Autores (2015).

Neste caso, sugere-se novamente uma abordagem voltada às técnicas da engenharia natural. Propõe-se, assim, que além da recuperação do sistema de drenagem, removase adequadamente (amparado por um estudo técnico de estabilização) o solo que exerce sobrecarga no muro.

Como outra possibilidade, sugere-se a aplicação de estacas vivas, de modo a fortalecer a estrutura de contenção. Alternativamente, poder-se-ia pensar na remoção do muro, substituindo-se por uma medida que intervenha o mínimo possível nas funções e nos processos naturais. Assim, poderse-ia formar um talude protegido por cobertura vegetal adequada. Isto implica na necessidade de uma área maior para a obra, por consequência da menor inclinação do talude. 


\section{OBRAS DE CONTENÇÃO DE ENCOSTAS EM BLUMENAU-SC: OLHARES À LUZ DA ENGENHARIA} NATURAL

Propõe-se, deste modo, manter os padrões técnicos comuns às duas abordagens, com a vantagem de eliminar a necessidade do muro de gabião-caixa. $O$ emprego de espécies arbóreas adequadas sobre a encosta pode auxiliar na "ancoragem" do solo e aumentar a interceptação de água pluvial, contribuindo significativamente para amortizar as vazões do escoamento superficial e sub-superficial.

\section{CONCLUSÃO}

Diante dos resultados apresentados, pode-se concluir que, das 10 obras investigadas, quatro apresentaram patologias visíveis e identificáveis e seis não apresentam patologias. Destacam-se os principais motivos dos problemas técnicos verificados: a presença de processos erosivos já consolidados devido à exposição do solo, o deslocamento excessivo da estrutura ("embarrigamento"), inclinações excessivas e/ou taludes com patamares inadequados (inclinação, superfície), ausência de calhas e outras estruturas de drenagem.

Salienta-se ainda a necessidade de revisão das obras avaliadas, por um profissional legalmente habilitado, tendo em vista os problemas levantados. Ressalta-se também a necessidade com mais urgência de atuar na obra da Rua Rep. Argentina, a qual apresenta indícios de colapso devido possivelmente à sua altura excessiva e problemas no sistema de drenagem (indicados pelas manchas de umidade).

No decorrer da presente investigação, ficou evidente a necessidade de se refletir e discutir a abordagem utilizada nas técnicas de engenharia, principalmente em períodos de caráter emergencial. Buscou-se então apresentar uma nova abordagem nas obras de contenção de encostas do município de Blumenau-SC: a abordagem da engenharia natural (ou bioengenharia de solo). Por meio do conteúdo exposto e da discussão lançada no presente trabalho, acredita-se ser possível recuperar as áreas estudadas e garantir diminuição no custo global, no tempo e, sobretudo, na sustentabilidade ambiental do sistema. Levando em consideração técnicas clássicas de engenharia civil, mas indo além, e também considerando a dinâmica complexa dos processos naturais (e sociais).

Por fim notaram-se fragilidades nas estruturas pesquisadas justamente pela desintegração das obras na dinâmica natural local. Acredita-se que o fortalecimento da abordagem de engenharia natural trará benefícios ambientais e sociais para áreas onde a intervenção de obras púbicas seja necessária e de significativa relevância. Além do mais, pode representar simbolicamente um passo importante na construção de uma mais harmoniosa relação entre o ambiente natural e construído.

\section{AGRADECIMENTOS}

Agradecemos ao CNPq e à CAPES pela bolsa de mestrado aos dois primeiros autores e à Agência de Desenvolvimento Regional do Estado de Santa Catarina (Gerência de Blumenau) pelo fornecimento dos dados de localização das obras pesquisadas.

\section{REFERÊNCIAS}

AUMOND, J. J.; SEVEGNANI, L. Descrição dos desastres: os escorregamentos de encostas. (2009). In: FRANK, B.; SEVEGNANI, L. Desastre de 2008 no Vale do Itajaí. Água, gente e política. 2009. Blumenau: Agência da Água do Vale do Itajaí.

AUMOND, J. J.; BACCA, L. E. A Tragédia Geoclimática catarinense: a paisagem como fundamento para a gestão pública. In: Gestão de natureza e sustentabilidade. Editores: Arlindo Philippi Jr., Carlos A. C. Sampaio, Valdir Fernandes. Barueri, SP: Manole, 2012. p.773744.

ATLAS DE SANTA CATARINA. Gabinete do Planejamento e Coordenação Geral - GAPLAN. Rio de Janeiro: Aerofoto Cruzeiro, 1986. p. 173.

BRASIL. Ministério das Cidades / Instituto de Pesquisas Tecnológicas - IPT. Mapeamento de Riscos em Encostas e Margens de Rios / Celso Santos Carvalho, Eduardo Soares de Macedo e Agostinho Tadashi Ogura, Organizadores. 
Brasília: Ministério das Cidades; Instituto de Pesquisas Tecnológicas - IPT, 2007.

BRASIL. Lei no 12.608, de 10 de abril de 2012 Política Nacional de Proteção e Defesa Civil. Brasília, DF: [s.n.], 2012. Disponível em: <http://www.planalto.gov.br/ccivil 03/Ato20 11-2014/2012/Lei/L12608.htm>. Acesso em: 19 ago 2014.

COPPIN, N.J.; RICHARDS, I.G. (Eds.). Use of Vegetation in Civil Engineering. Construction Industry Research and Information Association (CIRIA). Butterworths, London, 1990.

CORDERO A. et al. Estudo da precipitação máxima diária para Blumenau-SC e o evento de novembro de 2008. In: Anais... XVIII SIMPÓSIO BRASILEIRO DE RECURSOS HÍDRICOS. 2009. Disponível em: <http://ceops.furb.br/index.php/publicacoes/a rtigos?start=5 > Acesso em: 12 dez. 2014.

DURLO, M. A.; SUTILI, F. J. Bioengenharia: Manejo Biotécnico de Cursos de Água. Edições EST. Porto Alegre, 2005, 189p.: il.

EPAL - Empresa Pública das Águas de Lisboa. Introdução à Engenharia Natural. Volume II. 2011. FERNANDES, J. P.; FREITAS, A. R. M. (Org.). Disponível em: <http://www.epal.pt/EPAL/docs/defaultsource/epal/biodiversidade/publica\%C3\%A7\%C 3\%B5es/introdu\%C3\%A7\%C3\%A3o-a-

engenharia-natural.pdf?sfvrsn=10>. Acesso em: 11 fev. 2015.

FRAGA, N. C. As enchentes no Vale do ItajaíAçú/SC: das obras de contenção à indústria da enchente-a problemática ambiental e a relação homem/natureza na busca de soluções. Ra'ega - O Espaço Geográfico em Análise, v. 5, n. 1, p.125-148, 2001.

GENGO, R. C; HENKES, J. A. A utilização do paisagismo como ferramenta na preservação e melhoria ambiental em área urbana. Revista de Gestão \& Sustentabilidade Ambiental, v. 1, n. 2, p. $55-81,2013$.

GRAY, D. H.; LEISER, A. T. Biotechnical Slope Protection and Erosion Control. Florida: Krieger Publishing Company Malabar, 1982.
HIGLAND, L. M.; BOBROWSKY, P. O Manual de Deslizamento- Um guia para Compreensão de deslizamentos. Contribuição Trad. e adaptação para o Brasil por Paulo R. G. Rogério e Juarês J. Aumond. Edifurb, 2011.

HOLANDA, F. S. R. et al. Controle da erosão em margens de cursos d'água: das soluções empíricas à técnica da bioengenharia de solos. Ra'ega - 0 Espaço Geográfico em Análise, n. 17, p.93-101, 2009.

IBGE. Blumenau, Santa Catarina. 2018. Disponível em:< http://cidades.ibge.gov.br/xtras/perfil.php?cod

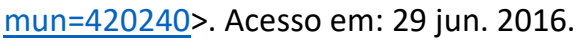

IPPUB - Instituto de Pesquisa e Planejamento Urbano de Blumenau - Blumenau. Perfil 1996. 284 p. 1996.

IPT. Ocupação de encostas. 1991. Instituto de Pesquisas Tecnológicas do Estado de São Paulo, SP.

JACOBI, P.R.; GÜNTHER, W. M. R.; GIATTI, L.L. Agenda 21 e Governança. Estudos Avançados, n. 26, v.74, p. 331-339, 2012.

KOBIYAMA, M.; MICHEL, G. P.; GOERL, R. F. Relação entre desastres naturais e floresta. Revista Geonorte, v.1, n.6, p.17-48, 2012.

LI, X.; MANDER, U. Future options in landscape ecology: development and research. The ecological society of America. v. 33, p. 31-48, 2009.

MORGAN, R. P. C.; RICKSON, R. J. Biotechnical Slope Stabilization and Erosion Control - a bioengineering approach. London: E \& FN Spon, 1995.

NASCIMENTO, D. J. F.; GOMES, M. F. V. B. Desastres naturais veiculados pela mídia: análise de conteúdo das notícias do jornal diário de Guarapuava. Ra'ega - 0 Espaço Geográfico em Análise, v. 32, p. 164-184, 2014.

NEVES, F. E. S.; HENKES, J. A. A gestão ambiental aplicada na implantação de rodovias no Estado de Santa Catarina: um estudo de caso de três rodovias catarinenses e a 
implementação de um plano de proteção ambiental ao meio socioeconômico. Revista de Gestão \& Sustentabilidade Ambiental, v. 2, n.1, p. 265-349, 2013.

OLIVEIRA, E. L. A.; RECKZIEGEL, B. W.; ROBAINA, L. E. S. Modificações na morfologia dos canais de drenagem da bacia hidrográfica do Arroio Cadena, Santa Maria/RS. Ra'ega - O Espaço Geográfico em Análise, n. 11, p.103-113, 2006.

PHILIPPI JR., A. et al. Interdisciplinaridade em Ciências Ambientais. São Paulo: Signus Editora, 2000, 327 p.

QUINTA-NOVA, L. C. A engenharia natural na reabilitação ambiental de áreas degradadas. Apresentação no 2을 Seminário Ibérico "Intervenções Raianas no Combate à Desertificação"- O Papel do Planeamento no Combate à Desertificação, 2013.

SANTOS, C. Mapeamento de riscos em Encostas e Margens de Rios. Brasil, Ministério das Cidades / Instituto de Pesquisas Tecnológicas - IPT. Mapeamento de riscos em encostas e margens de rios. Brasília: Ministério das Cidades, 2007.

SILVA, R. A. F. Aplicação da Engenharia Natural na Estabilização de Taludes. Universidade da Madeira. Centro de Ciências Exatas e da Engenharia (CCEE). Portugal. Dissertação de Mestrado. 127p. 2012. 